\title{
Understanding the Need of Mobile ICT Learning as an Elderly Learning Tool
}

\author{
doi:10.3991/ijet.v4i4.974 \\ S. Lam ${ }^{1}$ and W. Chung ${ }^{2}$ \\ ${ }^{1}$ Oxford University, Oxford, UK \\ 2 Tung Wah Eastern Hospital, Hong Kong
}

\begin{abstract}
With a rapid deployment of mobile devices, mobile learning gives rise to new possibilities for extending learning opportunities. Nevertheless, current research on mobile learning has mostly been aimed at enhancing learning of school or college students. In this light, the paper seeks to throw light on the potential of mobile learning for elderly. We describe in this paper a research study for examining needs that determine the adoption and usage of mobile devices by elderly population. The elderly are an often neglected group in product development and marketing, but they are the only growing age group in most developed societies. By using semi-structured interviews with a number of different stakeholders interested in elderly people, we identify a set of issues that need to be taken into account when designing strategy for the elderly learners. The results of our study indicate that elderly people are interested in using mobile devices and services, but these services need to deliver real value for them.
\end{abstract}

Index Terms-mobile learning, lifelong learning, mobile device, elderly learners

\section{INTRODUCTION}

Population ageing is a pervasive phenomenon. In the Asia- Pacific area for instance, people aged 50 and above are expected to take up approximately $31 \%$ of the total population by 2025 [1], while in Japan, population ageing seems to be more significant and one in three will be elderly in 2025 [2]. In addition to this, it is predicted almost one third of the working age population will aged 50 or over by 2050 in developed countries [3]. In this light, population ageing impresses people with an ongoing trend-ageing people will inevitably become an incremental part of the future workforce. Due to lack of enough qualified employees, ageing people nowadays have already been encouraged to join the workforce in some parts of world. In Europe, a marked rise has been found in the employment rate of people aged 55-64 from 36.6\% in 2000 to $43.6 \%$ in 2006 .

The requirement for the retraining of ageing learners is intensified, but research targeted at ageing learners is in short supply, also within the context of mobile learning. Unlike young and prime adults, ageing learners have unique learning requirements and traits. For instance, ageing individual needs a learning approach that facilitates the review of learning materials, as they incur a biologically-based decline in fluid intelligence, which impairs rapid processing of new information [4]. In addition, older learners may have lack of confidence and thereby resist trying something new. In this concern, mobile learning gains advantages as it tends to address these problems through bringing training into local areas and offering courses in less formal settings. Also, there is little extra economical and physical effort required for ageing people to learn via mobile devices in comparison to the computer-based or classroom-based learning approaches. Mobile learning process differs from a traditional e-learning process. Learning, communication and observation tasks are now taking place outside classrooms and other training facilities, which reveal the vulnerability of accessibility concepts. Reference [5] suggests that technology will become inextricably part of the "digital life" for many individuals around the world. The technology also offers a spectrum of educational opportunities and new options for student-technology partnerships in learning. Empowered with interactive multimedia presentational capabilities, handheld technology permits the delivery of a range of digital material such as video, audio, graphics and integrated media. If appropriately designed for the context, educationally useful interactive multimedia digital material like learning objects can be effectively delivered to students at any time, inside and outside of classrooms.

The elderly, the most rapidly growing segment of the industrialized world's population, have landed on the wrong side of the digital divide, the gap between information and communication haves and have-nots. In 1997, there was a $31.4 \%$ difference in the percentage of Internet users among people aged 35 or younger versus 65 or older, and by 1999 this difference had increased to $42.9 \%$ [6]. The rapid ageing of the population has implications for mobile learning device accessibility. As people age, they incur various impairments including loss of visual acuity, strength, fine motor control and coordination, and pain in the fingers, wrists, or other joints (e.g. due to arthritis). These impairments are particularly problematic for operating mobile devices, since devices' shrunken form factors, miniature buttons, small fonts, postagestamp screens, and low pixel counts make even ablebodied use difficult. As the baby boomers give way to Generation X, people who grew up with mobile devices and are accustomed to using them will be increasingly challenged to do so unless devices are made more accessible. Although there have been numerous efforts at making desktop computers accessible, there have been almost no efforts to improve mobile device accessibility. Mobile devices are only useful when design and software validation aspects have been taken into account [7].

\section{RELATED WORK}

The computer revolution is currently fuelled by rapid advances in versatile wireless communication devices (e.g., smartphones) and powerful handheld computers 
(e.g., Personal Digital Assistants or PDAs) that offer many of the standard functionalities of PCs. Because they are small, mobile and powerful, these new technologies are suited for many purposes. Mobile learning technology studies have been conducted on many Personal Digital Assistants (PDA) applications. However the studies usually focus on the younger generation, instead of the elderly. Stephen Brewster evaluated how multi-modal feedback can help improve data entry in PDA devices regardless of icon size. Multi-modal feedback involves the PDA device making sounds, tactile changes (i.e. vibration) or vision changes (button turns to inverse colors when touched) when PDA tasks are completed. He evaluated how college students performed inputting numbers into a PDA while sitting and walking. The experiments showed sound helped users input more numbers, however smaller buttons required more "workload" [8]. Using PDAs for voice recordings is becoming a popular way to get user feedback in situ. Reference [9]. integrated voice recordings into their context-aware experience sampling tool to obtain feedback from participants. In the future, we see researchers using the PDA audio recorder for voice diaries to allow users to quickly record problems or comments about applications for mobile usability testing. However, in order to reduce educationally caused differences in the use of mobile learning systems, further research efforts are thus required in order to be able to offer ability- and talentadapted help systems as well as accordingly adapted dialogue interfaces. A major prerequisite that as a basic architectural principle determines systems design in this respect demands support of target-achieving "evolutionary learning".

The rapid ageing of society and the growing young-old digital gap are widely recognized and are strong motivators for achieving Universal Accessibility [10]. A variety of user interface design guidelines have been developed over the years, some of which seem broadly consistent with evidence of age-related declines in cognition [11] and [12]. However, we believe that current guidelines encompass only a subset of the relevant human-factors data, and seem to have evolved more from intuition than systematic empirical research. Consequently, the guidelines have blind spots in essential areas; moreover, where guidelines do exist, they can be hard to translate into specific user interface characteristics. We advocate the development of guidelines that are more firmly anchored in a comprehensive understanding of adult lifespan developments, supported by research on their validity and reliability.

Educational studies show that a number of pedagogical and technological issues need to be addressed if handheld technology is to be effectively applied in learning [13]. Reference [14] have called for studies to explore how handheld devices might more effectively support teaching and learning and especially their multimedia presentational capabilities, from a technical perspective it is possible to deliver a range of learning objects and other educational materials. Reference [15] suggested that these devices offer increased flexibility for students to access and use learning objects. However, at this stage there are very limited guidelines suggesting effective design considerations for learning objects when presented via handheld devices, however the challenge is mainly related to the size of the screen [16]. In addition, mobile learning is not all about technical in nature but rather on information ac- cess. Reference [17] states: "In reality, the educational need is not to have a computer in the hands of every student but for students to be able to access appropriate processing power, software and data as required."

\section{EARLIER RESEARCH ON LIMITATION OF MOBILE LEARNING}

Many researchers accept that mobile learning can, and probably will, play a more important role in lifelong learning processes. However, due to technical limitations, as well as human psychology, mobile learning is still limited to an assistance-only function. Traditional classroom learning, or even distance learning through interactive educational television classrooms (e-learning) should not be brushed aside, and the real potential of mobile learning should not be exaggerated.

\section{A. Psychological}

Mobile devices such as mobile phones or PDA will mainly be used for communications, not for learning purposes. Mobile learning does not replace traditional learning, but is just another way of learning using a new technology. The fundamentals of learning still do not change with mobile learning [18]. Even in Japan, students, who are the group of people most likely to best use of mobile learning, seldom use their mobile devices for educational purposes [19]. In short, many people would lack the motivation needed to use their mobile devices for learning purpose consistently. Although medical researchers have so far not found any evidence to prove that there is a relationship between mobile devices use and brain or aural impairment [20], many people still suspect that frequently using mobile phones, for example, is the reason for the increased incidence of brain tumors and other brain or aural diseases. It has been shown that mobile phone radiation actually does cause increases in blood pressure [21]. The author believes that it is particularly the case for elderly learners' consideration.

\section{B. Pedagogical}

Researcher Singh augured that it is hard to follow up on the learning achievements in mobile learning. Individuals need to take full responsibility for their own learning and we believe that it is particularly hard for the elderly learners. Without on-site supervision, course organizers find it difficult to administer a test and the high level of interaction between educators and learners [22]. Studies and statistics show that between $20 \%-30 \%$ of those students who begin mobile learning courses do not finish [23]. In the mobile learning environment, the lack of a firm framework tends to encourage laziness; therefore a strict selfdiscipline, which many adolescents lack, is required. Also, in mobile learning there is an absence of a "learning atmosphere". According to the survey conduced by Bounhnik \& Marcus [24], many students reported that distance learning (which, of course, would include mobile phone learning) was less efficient, when compared to a "face-to-face" learning format, and required them to devote more time to learning the subject. Bouhnik and Marcus also mentioned that as mobile phone learning is a method for learning on the move, it is unavoidable that the surrounding environment will often interrupt the learning process. Learners cannot focus all of their attention on learning while on the move. If the interruptions and dis- 
tractions occur frequently enough, educators believe the learners will gradually become resistant to mobile learning in the same way as has been found in other transitory learning environments. The author believes that attention focus is always a problem for elderly learners. Furthermore, in practice, mobile learning materials designers find it is currently impossible to design a generic version for all platforms [25]. Teachers have to design different learning materials specifically for particular mobile platforms. The Lack of standardization and compatibility of different mobile devices have to be comprised reaching a standard or agreement among those software companies [26] in order to make mobile learning more common.

\section{Technical}

Small screen size and low image resolution are the main problems for learners especially elderly learners. Most of the mobile device screens' size might be all right for viewing texts for a short time, but usually not for longer than one or two minutes, as for longer than that people's eyes become tired. Learners have to struggle with the small fonts on the small screen. This limitation will keep a lot of middle-aged or elderly learners from taking mobile learning courses [27]. Current mobile device input is not at all user-friendly. Slow and inconvenient input methods are real problems. To input a word in any language, users may have to hit a key several times even to find the right letter. The real word input speed is still less than $1 / 10$ the input speed when they use a computer keyboard [28].

\section{RESEARCH METHDOLOGY}

The research was carried out in two stages, using two very different methodological approaches: While the first stage was based on a review of already existing material, the second stage relied on original primary research. The research addressed and made use of older people's views and was guided by the University of Oxford research ethics committee rules.

(1) In the first stage, a desk review of relevant policy documents reflecting the latest trends on elderly education using ICT mobile tools was carried out. Research methods required for this stage included a literature review, documentary analysis of policy documents, and some secondary data analysis.

(2) In the second stage, original empirical research was conducted. Qualitative expert interviews were chosen as the appropriate research method to gather exploratory but nevertheless detailed information on the objectives of the research. This approach was essential to collect the required data on 'examples of good/best practice' and the measurement of old-age ICT ability and mobile ICT tools usage in particular. It also proved very useful for obtaining detailed background knowledge, public debate and variation in various setting.

Empirical part of our qualitative research study was based on semi-structured interviews with persons who represented different focus groups: mobile device manufacturers, mobile operators, voluntary organizations aiming at educating elderly people, public and private home care and elderly nursing homes, as well as welfare development institutions. This was necessary to extend the range of the research and to minimise the risk of relying on the inevitably one-sided perspective of any particular social actor. In the initial stage of the study, a number of the above mentioned focus groups who had previously used handheld technology for personal and educational purposes, were interviewed (face-to-face). Over fifty such individuals were identified across a number of educational institutions in Hong Kong who subsequently accepted an invitation to participate as respondents. The interviews were conducted in a semi-structured manner and began by asking the respondent to outline his or her prior experience with handheld technology. The interview progressed to discussion in relation to the small screen and this was facilitated by various handheld device and small selection of learning objects from the Learnactivity web site (see http://www.learnactivity.com/lo/). These learning objects were originally developed for computer-based delivery over the Internet and were downloaded into the handheld device for the purpose of this study. The respondents were encouraged to interact with the learning objects, which were selected to also permit demonstration of various modalities (e.g., text, visuals, audio). Ideas about possible contexts for educational applications of these learning objects were also explored with the respondents. Interviews and development of understandings were greatly facilitated by the interviewer's knowledge and extensive experience with the design of educational multimedia material. During the interview, the researcher was able to comprehend suggestions and concerns by participants, and to immediately speculate and table possible design solutions for discussion. The discussions were mainly based on the particular expertise of each interviewee, but also the subjective opinions and experiences of the interviewees were of interest. All interviews lasted from one to two and a half hours, and were recorded for reference checking. The interviews were transcribed and sent back to the interviewees for review. After review and corrections, the interviews and emerged themes were analyzed.

\section{RESULTS}

\section{A. Communication with mobile devices}

Nearly $100 \%$ of the elderly people in the survey find the small buttons of a mobile device hard to use, and the small text on displays and interfaces difficult to read, problems that are compounded if they are suffering from age-related frailty or Parkinson's disease that impairs motor skills.

Some cognitively and physically impaired elderly learners being interviewed in the survey were nonspeaking. Communication for these group with the world is limited to iconic keypads that display icons for common words - primarily nouns and verbs - that, when pressed, are synthesized through a speaker. These keypads are designed to be simple and limit communication to a small number of alternatives, while keypads for the unimpaired can produce a wide range of words at the cost of complexity (hundreds of icons), with many words requiring sequences of keystrokes. The survey results report that many elderly can define meanings for unassigned keys, existing keypads are relatively inflexible, which makes adding new vocabulary difficult, thus limiting the range of conversation. These keypads can be challenging to learn and are often abandoned out of frustration. Over $70 \%$ of the respondents request further development in keypads adapting to the user. The keypad for PDA is displayed on a touch sensitive screen. They need keypad with more obvious textual and auditory feedback when pushing keys or navigating menus. Keys should be clearly embossed and 
positioned so that a user can not press several keys by mistake at the same time. Another related problem is created by the keypad lock. Switching the lock on and off typically requires pressing two buttons in a sequence and typically quite quickly so.

\section{B. Need for vision in screen}

For a learning object to be cognitively engaging and practically useful, their design must leverage not just text and/or audio but more importantly visualization and interactivity, where text is used for labeling, pointers and short content messages only when necessary. Reference [29] suggests that visuals can communicate complex ideas with clarity, precision, efficiency and convey the most ideas in the quickest time in the small space. It is particularly the case for elderly learners. According to the survey results that elderly users were having vision difficulties in screen in the following cases; reading text in menu and text message especially when font is not gothic, and when color contrast between text and background is not obvious. They need bigger screen with big font size, gothic font type, obvious color contrast, obvious design or way to add text for status icons, big obvious clock setting, and a way to check photo with other big display equipment because of vision problem.

Another important feature is that icon location should provide enough context to guide icon selections as elderly learners especially cognitively impaired group have great difficulty to cope with changing locations of icons change between contexts. For this reason, inter-keystroke interval as suggested by computer experts- the time it takes the user to find the next key - is an obvious training signal for elderly. Adaptation should minimize this interval, allowing more efficient communication, and thereby increasing user acceptance.

\section{Interaction with mobile devices}

One common point being agreed by all parties in the survey that both the characteristics of the display devices (small or no screen) and the cognitive, sensory, and motor skill characteristics of the elderly population imply that traditional user interfaces relying on icons and textual labels are inappropriate for effectively communicating with users. According to both users and computer designers that there is a need to develop novel interaction techniques and interface designs based on alternate modalities, such as audible and interface designs based on alternate modalities, such as audible feedback and speech. According to the survey results, computer designers highlighted several solutions to elderly-related problems with innovative interfaces:

1. Reduction of operations offered at once to avoid excessive interface complexity caused by excessive number of functions;

2. Minimizing the trees of options to avoid the presence of layered menus, causing a lack in working memory about the existence of invisible options;

3. Realizing specific keyboard commands instead of mouse drag and drop., complicated for elderly people at motor level;

4. Giving immediate feedback about any selection on screen to simplify the understanding of the correctness of the operations;

5. Maintaining the consistency of the appearance of the interface to minimize the confusion of the user seeing changes when looking at several screens using the same interface.

\section{Mobile device interface}

In designing proper mobile learning devices all usability risks should be taken into consideration. Especially in the case of mobile devices and their interfaces all usability factors are crucial. The major interface problem raise by computer designers in the survey is that an overriding multi-functional interface is needed for all possible combinations of tasks and user populations supporting learning in a variety of contexts over long periods of time. An interface design that represents to its context of use providing the means for learners to describe and preserve their reflections on different setting environments and also needs to enable learning to learn, through ways of organising ideas, memories and personal resources to support long-term learning. We should also design adaptive user interfaces; i.e., interfaces that change over time to better support repetitive tasks and particular behavioral characteristics of each user.

\section{E. Focused Attention}

One of the major problems reported by the users in the survey is divided attention which is the distribution of processing resources among multiple simultaneous tasks or rapidly switching from one task to another. A handheld device personally assists and supports an individual in his or her activities, e.g., conducting a business, making scientific inquiry, planning a trip, creating art, learning, on so on. Attention is often divided, for example an individual might be undertaking some tasks simultaneously or in a variety of modalities when drawing on the assistance of handheld devices. However, age-related deficits increase with the increase of the stimulus complexity and decrease with the increase of the amount of practice in the task.

Elderly users need restrict functions to the extent that they often use. They feel that mobile device has too many functions they don't use. They are interested in functions that are not related to their everyday life.

Another major concern was the impact of prolonged use of handheld-based learning objects on their health and in particular to possible eye-strain of elderly learners. Applying the above mentioned problems to design of mobile learning objects for elderly learners, computer designers recommended in a way that provides for learning taskcentered information to be provided in a single action on a small screen. Learning object design should be taskoriented. When designing mobile learning, educators should focus on the design of the learning as much as on the design of the technology / system. Although it is relatively straightforward to design a piece of technology that is usable, robust, and delivers impressive functionality, the experience should go beyond the technology, with clear purpose for the teaching and learning. Placing the learning experience in the related learning domain and consulting pedagogical approaches appropriate for the type of learning being supported is central: the technology design should go hand in hand with the instructional design, involving expert educators and learners as well as technology designers.

\section{F. Enhancing learning experience}

Evaluation of the interview results with the learners shows that elderly learners enjoy using mobile devices for 
learning and report increased motivation as a result of this use. A number of factors have been identified contributing to the high affective value of mobile learning by elderly learners: control over goals, ownership, fun, communication, learning-in-context, and continuity between contexts. However, educators have rather different point of view under the same area that the use of (mobile) technology to enhance an activity comes with a danger to move the learner's focus from the real activity onto the (mobile) technology. Mobile technology interference, however, can take a number of forms as mentioned by educators in interviews, including upsetting the balance on social relationships by providing opportunities for inclusion/exclusion; imposing too much overhead in manipulating the device itself; and imposing learning opportunities when the person has no desire to learn or to sacrifice time dedicated to non-learning activities.

\section{CONCLUSION}

In designing proper mobile learning devices all usability risks should be taken into consideration. Especially in the case of mobile devices and their interfaces all usability factors are crucial. When testing a www-page, the context and environment are of second interest and the traditional design principles presented by Reference [30] apply. Based on the consideration of cognitive ergonomics of the elderly, this study proposes some practical guidelines for computer designers, as follows.

1. The interactions in human-computer interface should based more on physical characteristics to build up the system images as the elderly are more familiar with physical operations. For example, Key pad should be clearly embossed and positioned.

2. The levels of hierarchy should be limited to a minimum in order to be memorized easily. For the learning materials, learning task-centered information to be provided in a single action on a small screen to avoid the divided attention problem.

3. For addressing impairments in vision, speech and hearing, psychomotor skills, attention span, and memory:

- Use layout simplicity, clarity, and consistency

- Use lower frequency tones for sounds

- Design speech recognition software to cope with slower speech

- Allow double-click speeds to be slower

- Avoid delays and distractions to minimize short term memory loss

- Use only simple, relevant graphics

- Prefer short text or lists to paragraphs of text

- Don't rely on color alone

- Provide larger graphics and click targets

4. The functions of mobile devices should be made gradually accessible in order to prevent unnecessary confusion of temporarily unneeded functions, such as $\mathrm{mp} 3$ player.

One of the main objectives is social inclusion: especially the integration of older people and people with disabilities into the information society. The means to achieve this is to design mainstream products and services to be accessible by as broad a range of users as possible operating within the widest possible range of situations.
The idea is to offer means and recommendations to design better usability and accessibility for environments and to promote format standardisation.

\section{REFERENCES}

[1] W. Watson. Ageing workforce 2006 report, 2006, Available from: http://www.watsonwyatt.com/images/database uploads/ ageing ap 06/A P_AgeingWorkforce2006.pdf. Accessed 5 January 2008 .

[2] BBC, "Fears over Japan's ageing population", http://news.bbc.co.uk/1/hi/world/asiapacific/1083097.stm. Access 10 April 2008.

[3] UN and DESA. World Economic and social survey 2007: development in an ageing world. New York: United Nations publication, 2007, pp. 24-24.

[4] C. Niessen, "Age and learning during unemployment", Journal of Organizational Behavior, 27(6), pp. 771-792, 2006. (doi:10.1002/job.400)

[5] J, Attewell. Mobile technologies and learning - a technology update and m-learning project summary, Learning and Skills Development Agency, 2005. Available from http://www.LSDA.org.uk

[6] P, Graf., K, Li. and J, McGrenere. Technology usability across the adult lifespan, in Proceedings of British HCI '2005.

[7] Holzinger and M. Errath. "Designing Web- Applications for Mobile Computers: Experiences with Applications to Medicine," in User Interfaces for all. Lecture Notes of Computer Science, C. Stephanidis and C. Stary, Eds. Berlin, Heidelberg, New York: Springer, 2004.

[8] S, Brewster. Overcoming the lack of screen space on mobile computers. Personal Ubiquitous Computing, 6(3):188-205, 2002. (doi:10.1007/s007790200019)

[9] S. S. Intille, E. M. Tapia, J. Rondoni, J. Beaudin, C. Kukla, S. Agarwal, L. Bao, and K. Larson. Tools for studying behavior and technology in natural settings. In A. K. Dey, A. Schmidt, and J. F. McCarthy, editors, UbiComp 2003: Ubiquitous Computing, pages 157-174. Springer, October 2003.

[10] B, Shneiderman. Universal usability. Communications of the $A C M$, 5, 84-91. ACM Press, 2000.

[11] F. I. M, Craik \& T. A, Salthouse. (Eds.).The handbook of ageing and cognition. Hillsdale, NJ: Erlbaum Associates, 1992.

[12] P, Graf, \& N, Ohta. (Eds). . Lifespan memory development, 2002. MIT Press.

[13] L. A Clyde.. M-learning. Teacher Librarian, 2004 32(1), 16-45.

[14] M,Sharples, D, Corlett, \& O, Westmancott. The design and implementation of a mobile learning resource. Personal and Ubiquitous Computing, 2002 6, 220-234. (doi:10.1007/ $\underline{\mathrm{s} 007790200021)}$

[15] C, Bradley, R, Haynes, \& T, Boyle. Design for multimedia mlearning. Retrieved, May 24, 2006 from http://newsletter.alt.ac.uk/ e_article000552781.cfm.

[16] K, Luchini, C, Quintana, \& E, Soloway. Design guidelines for learner-centered handheld tools, 2004. CHI, 6(1), 135-141.

[17] P, Alpion. Laptop orthodoxy: Is portable computing the answer for education. Journal of Australian Educational Computing, 2001. Volume 14, No. 1. pp. 5-9.

[18] F. H. A, Razak. Understanding interaction experience in mobile learning. Computer Human Interaction: Proceedings Lecture Notes in Computer Science, 2004, 3101, 672-674.

[19] P, Thornton, \& C, Houser.. Using mobile phones in English education in Japan. Journal of Computer Assisted Learning, 2005, 21, 217-228. (doi:10.1111/j.1365-2729.2005.00129.x)

[20] U, Sievert, S, Eggert, \& H.W, Pau. Can mobile phone emissions affect auditory functions of cochlea or brain stem? Otolaryngology - Head and Neck Surgery, 2005, 132(3), 451- 455. (doi:10.1016/j.otohns.2004.09.064)

[21] S, Braune, C, Wrocklage, J, Raczek, T, Gailus, \& C. H. Lüching. Resting blood pressure increase during exposure to radiofrequency electromagnetic field. Lancet, 1998, 351, 1857-1858. (doi:10.1016/S0140-6736(98)24025-6) 
[22] H, Singh.. Leverageing mobile and wireless Internet, 2003. Available from http://www.learningcircuits.com/2003/sep2003/ singh.htm

[23] A. P, Rovai.. Building sense of community at a distance. International Review of Researc in Open and Distance Learning, 2002, Available from http://www.irrodl.org/content/v3.1/rovai.html

[24] D, Bouhnik, \& T, Marcus. Interaction in distance-learning courses. Journal of the American Society for Information Science and Technology, 2006, 57(3), 299-305. (doi:10.1002/ asi.20277)

[25] J, Attewell. Mobile technologies for learning, 2005. London, UK: Learning and Skills Development Agency

[26] R. J, Bates, \& D. W, Gregory. Voice \& data communications handbook, 2001 (4th ed.). Berkeley, CA: McGraw-Hill.
[27] A, Bryan. Going nomadic: Mobile learning in higher education, 2004. EDUCAUSE, 39(5), 28-35.

\section{AUTHORS}

S. Lam (sancheslam@gmail.com) was with the Department of Education, Oxford. He is now with the Social Sciences Division, Oxford University, UK.

W. Chung (winnie0903@hotmail.com) is with the Social Work Department, Tung Wah Eastern Hospital, Hong Kong.

Submitted 18 June 2009. Published as resubmitted by the authors on 18 November 2009. 